\title{
Strategies For Successful Diversity Training In Corporate America
}

Jane Whitney Gibson, (E-mail: jwgibson1@aol.com), Nova Southeastern University

Cheryl Kimis, (E-mail: gkimis@ @eo.rr.com), Baker College

\begin{abstract}
Corporate America is facing both a workforce and a customer base which are increasingly diversified. Diversity training initiatives are proliferating as a way to not only avoid legal problems but, more importantly, to find strategic advantage in this diversity. This article investigates the fundamentals of diversity training by answering a series of questions including: What is diversity training? Why is diversity training needed? Who is doing diversity training? When does diversity training fail? More importantly, the article focuses on strategies by suggesting how to design a successful diversity training program.
\end{abstract}

\section{INTRODUCTION}

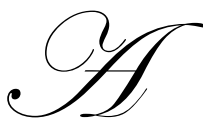

$\mathrm{t}$ the start of the new millennium, American corporations are faced with an increasingly diverse customer base as well as an increasingly diverse workplace. The smart organization will recognize the opportunities as well as the challenges inherent in these changes. A special report by the Hudson Institute entitled Work Force 2000: Work and Workers in the $21^{\text {st }}$ century, reported that in the last 12 years of the $20^{\text {th }}$ Century, only 15 percent of new employees were native white males whereas the other 85 percent were comprised of women (42 percent) and native non-whites and immigrants (43 percent). (Nixon \& West, 2000). Because of this increased diversity in the workforce, many organizations have implemented diversity training programs. When employees have positive relationships in a diverse workplace, the organization becomes one where more people would like to be employed. Poorly organized and conceptualized diversity training programs, however, can be detrimental to the organization.

This article investigates the fundamentals of diversity training by answering a series of questions including: What is diversity training? Why is diversity training needed? Who is doing diversity training? When does diversity training fail? More importantly, the article focuses on strategies by suggesting how to design a successful diversity training program.

\section{WHAT IS DIVERSITY TRAINING?}

Early efforts at diversity training were little more than an organizational palliative designed to augment affirmative action programs and cause employees and other stakeholders to feel that the organization was doing something to assure fair treatment in the workplace. Today, diversity training is neither another form of affirmative action nor an issue of Equal Employment Opportunity. (Von Bergen, Soper \& Foster, 2002). Diversity training is a strategic initiative designed to make the workplace more inclusive rather than exclusive. In earlier manifestations, diversity initiatives were aimed at helping managers control the differences. Now, diversity training aims to help the organization capitalize on those differences in an increasingly global setting. Nor are those differences limited to race and sex, although these are familiar focal points of such training. Diversity training aims at creating sensitivity and improved communications in the face of all differences. The authors call this "Getting by the Spinach." The following boxed example illustrates the fundamental concept that differences make us uncomfortable and when we are uncomfortable communication (and, by extension, productivity) suffers. 


\section{Getting By The Spinach}

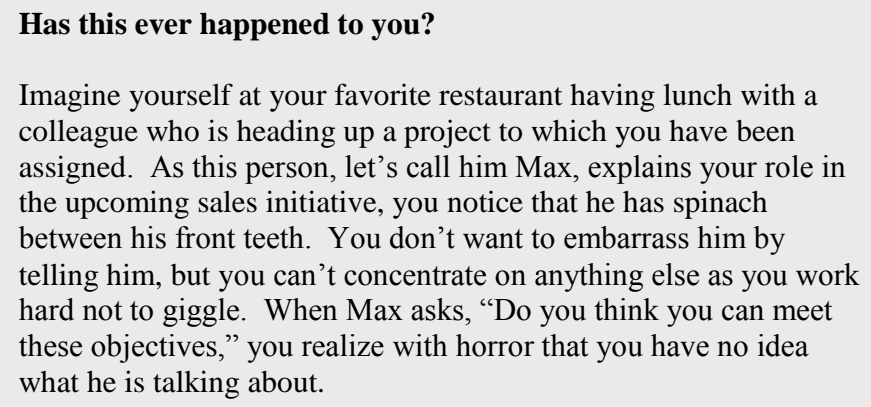

Each day we have to "get by the spinach" or risk wasting time concentrating on personal characteristics such as age, gender, nationality, speech patterns, weight, sexual orientation, appearance, physical disabilities, socioeconomic status, or religious beliefs. The latter is a particularly potent area of concern since $9 / 11$ and the resultant widespread prejudice against people of the Muslim faith. (Katz, 2003) Diversity training aims to help us understand and appreciate differences and to communicate effectively.

At its most basic, diversity training aims not so much to change attitudes, although that would be optimal, as to change workplace behavior. In 2003, the City of Largo, Florida sent all 1,000 employees to diversity training. The City Manager put it this way: "We don't own your mind, but while you're on the job, we own your mouth." (Stanton \& Clegg, 2003). Diversity training programs vary from the rudimentary 4 hour workshop presented to the Largo employees to multi-day programs some of which are supplemented on a yearly basis.

It is found that the most modest training programs typically focus on individual attitudes, whereas more comprehensive efforts typically add consideration of individual behavior and employers' human resource policies and systems. The most comprehensive initiatives.... are full-scale efforts to change workplace cultures.

(Bendick, Egan, \& Lofhjelm, 2001, 10)

The format of courses also varies tremendously from the typical face-to-face classroom setting to experiential trips like visiting an art museum and interpreting individual perceptions of people in assigned paintings. (Anonymous, 2004). Some diversity training is now being done on the Web. (Fasig, 2004).

To fully understand what diversity training is all about, the reasons for such training should be examined.

\section{WHY IS DIVERSITY TRAINING NEEDED?}

It is easy to argue that a more diversified workforce has a competitive advantage in a more diversified marketplace. There are three main reasons for embracing diversity training in organizations. (McLaughlin \& Clemons, 2004). First, it can be argued that in recognition of the fact that the U. S. labor force is becoming more diverse, implementing a diversity training program is just the correct thing to do.

Second, a less altruistic reason is that diversity training can be shown to be strategically important to the bottom line. It seems logical that a cooperative, professional workforce will increase productivity and reduce costs through the better working relationships among the employees. A 2001 study done by the Society for Human Resource Management and Fortune Magazine of Fortune 1000 companies and the Top 100 Companies to Work For reported productivity-related benefits from diversity initiatives including diversity training. These included improvement in corporate culture (76 percent), recruitment ( 77 percent), client relations (52 percent,) and an increase in employee retention (14 percent). (Management training...2001). Another study pointed out that companies recognized as one of the "best places for racial minorities to work had a total five year return to shareholders of 201 
percent versus 171 percent for the S\&P 500." (Salomon \& Shork, 2003, 38) Says Mauricio Velasquez, President of Diversity Training Group:

You are not looking at diversity training because 'it is the right thing to do.' You are looking at diversity training because your employees and customers demand it. Corporate diversity efforts are about money, business and the bottom line.

(Barbian, 2003, 45)

The third reason for initiating diversity training may be the most compelling reason for many organizations; i.e., the fact that diversity training may help the organization defend itself against legal cases arising from the many equal opportunity laws since courts typically take a long look at corporate preventive efforts in discrimination cases.

Accepting the need for diversity training is one thing, but who in Corporate America is actually doing this type of training?

\section{WHO IS DOING DIVERSITY TRAINING?}

The question of who is doing diversity training in Corporate America can be looked at from two perspectives: (1) Which companies are delivering this training, and (2) Who is actually doing the training?

The last decade of the $20^{\text {th }}$ Century saw a rapid growth in diversity training in Corporate America. In the late 80s this type of training wasn't even listed among the common corporate training programs in Training Magazine's annual survey, but by 1994, more than half of the companies surveyed had inaugurated some type of diversity training. (Roberson, Kulik \& Pepper, 2001). By 1997, one study showed that the majority of Fortune 500 companies were offering this type of training. (Hemphill \& Haines, 1997).

It should be noted that diversity training is not relegated to any one sector of the economy. While more comprehensive programs are often found in larger companies, small and medium-sized organizations in both the private and public sector are also seeking the benefits of diversity training. Examples abound everywhere around us. Some programs are relatively new.

- $\quad$ The 49ers took diversity training as a team requirement during spring training in 2004. The players were so enthusiastic about it that the NFL is now looking into providing diversity training on a wider basis. (Hack, 2004).

- In 2004, over 60,000 central North Carolina residents have taken diversity training including the staffs of the Guilford Country schools, the public defender's office, district judges, and the Waffle House. (Kelly, 2004).

- In the shadow of a lawsuit by six city employees charging discrimination, all city employees in Niagara Falls have been mandated to watch a two videotape diversity program this year. (Norheim, 2004).

Other diversity training initiatives have been ongoing.

- In the spring of 2004, Proctor \& Gamble rolled out a four module Web-based training program as the newest component of the diversity training they've been doing for 30 years. (Fasig, 2004).

- $\quad$ Denny's continues widespread diversity training among its managers and staff which started after a 1993 lawsuit charging systematic discrimination against minority customers. (Bendick, Egan, \& Lofhjelm, 2001).

- $\quad$ The workforce of Owens Corning continues to diversify per former CEO Glen Hiner's mandate to bring diversity training to all OC employees continues as part of a much broader diversity initiative. In 2004, OC added its first annual Diversity Leadership Conference to its roster of diversity training programs. (http://www.owenscorning.com/diversity2005/index.asp).

The second question posed under this section is: Who is actually doing the training? As would be expected with any relatively new training arena, a sizeable cadre of expert trainers has evolved to offer their services to Corporate America. As might also be expected from those familiar with the early days of organizational development 
consulting, some of these trainers have little training or experience themselves and tend to offer canned programs which may or may not be modified for the individual corporate client. Fortunately, the choices of legitimate diversity trainers are quite robust. On the for-profit side of the aisle, there are myriads of training consultants and lawyers who do this type of work. In the non-profit arena, there are universities, professional associations, and anti-bias organizations. As in all cases, the buyer needs to beware of the backgrounds and interests of the providers. Some of the anti-bias organizations, for example, will understandably focus on diversity issues concerning their own constituencies. A solid diversity training module on diversity issues concerning the visually impaired population might be perfectly fine, but could not, in itself, be considered a diversity training program.

\section{WHEN DOES DIVERSITY TRAINING FAIL?}

Successful diversity training relies on corporate commitment and a carefully planned strategy. When formulating such a strategy, it is helpful to examine the typical reasons that diversity training has failed in the past. One of the major problems with this type of training is cost. The daily cost of a diversity trainer has been estimated to be $\$ 2000$. Most of the diversity consultants recommend that organizations start out with a culture audit when planning a diversity training program in order to determine what that organization needs. This can add another $\$ 100,000$ to the start-up cost, possibly explaining why diversity training occurs most often in large organizations that can better afford this investment. (Von Bergen, 2002).

The rapidly increasing demand for diversity trainers has also led to a large number of unqualified, selfproclaimed diversity experts much like in the early days of organizational development interventions. Many of these trainers are primarily motivated by quick money and use boilerplate programs regardless of the needs of the organization. Another common problem with trainers is that they may be advocates for a particular group or point-ofview. (Von Bergen et. al., 2002) In the latter case, the trainer may only cause more problems in the organization by reinforcing stereotypes and increasing hostility.

Another potential problem with diversity training is the length of the training. Half-day to full-day sessions are probably not nearly enough to cover what is needed for an organization. These sessions just scratch the surface by raising some awareness about diversity issues, but they are not long enough to get to the deeper issues that may be effecting the organization. (Bendick et. al., 2001) Rynes \& Rosen (1995) have suggested that the topics covered in diversity training sessions are too emotional for a single session. Also correlated with the length of the training program is that the definition of diversity brought out in these short sessions may be too narrow. Many diversity programs do not differentiate between diversity, affirmative action, and Equal Employment Opportunity issues but instead focus on the legal aspects of diversity. (Overmyer Day, L., 1995).

Another problem is that many diversity training programs stress an environment of political correctness. Karp \& Sammour (2000) found that being politically correct might actually cause negative effects. Employees may start to think that there is something wrong with a group or person being the way they are because of the use of politically correct labels. Is "hearing impaired" really a more accurate term for someone being "deaf" or "hard-ofhearing" or does it imply there is something wrong with being deaf?

After considering some of these potential pitfalls for diversity training, here are some strategies for designing a successful training program.

\section{HOW TO DESIGN A SUCCESSFUL DIVERSITY TRAINING PROGRAM}

Figure 1 suggests a series of steps that companies may find useful in initiating a diversity training program. 


\section{Step One Is To Ensure Top Management Support}

Diversity initiatives often start in the board room or at least with the CEO. Many companies have designated a top level manager in charge of diversity, especially in large companies. Often, diversity finds a prominent mention in the goals of the company or the vision statement. In the mission statement of Southwest Airlines, for example, there is clear mention of the importance of diversity:

Figure 1: Strategies For A Successful Diversity Training Program

\begin{tabular}{|l|l|}
\hline 1 & Ensure top management support \\
\hline 2 & Enlist expert trainers \\
\hline 3 & Perform a cultural audit for need assessment \\
\hline 4 & Solidify program goals \\
\hline 5 & Decide on a training format \\
\hline 6 & Train managers first \\
\hline 7 & Train all employees \\
\hline 8 & Build in assessment and feedback \\
\hline
\end{tabular}

We are committed to provide our Employees a stable work environment with equal opportunity for learning and personal growth. Creativity and innovation are encouraged for improving the effectiveness of Southwest Airlines. Above all, Employees will be provided the same concern, respect, and caring attitude within the organization that they are expected to share externally with every Southwest Customer.

(The Mission of Southwest Airlines, http://www.southwest.com/about_swa/mission.html, 2.)

Management must show their patronage and commitment for a diversity training program. Bendick, et. al. (2001) found that employees were much more willing to approve of and participate in diversity training programs knowing that they were fully supported by upper management. One way for management to show its full support of diversity programs is by modeling and setting a good example. (Wentling \& Palma-Rivas, 1999). Rynes \& Rosen (1995) suggested that one way to accomplish this is to increase the diversity in their own ranks. Adding more diversity to upper management positions demonstrates to employees that management is practicing what it preaches. Along with their full support, management must clearly communicate their definition of diversity, their objectives of the diversity training program, and how it relates to the organization's operating goals. This ensures that employees will know why it is important for them to make every effort to comply with the program.

\section{Step Two Is To Enlist Expert Trainers}

This does not necessarily mean that a given organization has to go to outside consultants. There may be experts already in the training department or on the diversity staff, if there is such a group. In either case, organizations must ensure that they have obtained qualified and effective trainers who have a vast knowledge of diversity issues and are able to effectively communicate that knowledge to employees. Personal and interpersonal skills are a necessity as the trainers must be able to lessen the employee's resistance to the program and mitigate conflict when the need arises. It is important that the consultants or diversity staff are brought into the process at the very beginning so that they can be instrumental in doing a needs assessment and designing an appropriate training program.

\section{Step Three Is To Perform A Cultural Audit For Needs Assessment}

Each organization is different with its own unique diversity characteristics. There is no one single way to use diversity training to meet the needs of every organization, so training programs should be customized to fit each organization's requirements. Typically trainer/facilitators interview representative groups of employees to assess attitudes, challenges, and problems concerning diversity in the organization. As part of this, the interviewers will want to ascertain what types of behavior are rewarded in the organization as these are the behaviors that will be 
strengthened. How are these behaviors aligned with goals as they relate to diversity? Cultural audits examine the diversity statistics within the organization and gauge the perceptions of employees regarding diversity issues. (McLaughlin \& Clemmons, 2004).

\section{Step Four Is To Solidify Program Goals}

Once the assessment phase is complete, the manager(s) responsible for the program and the consultant/trainer/facilitator need to sit down and sort through the summary of the audit. In many cases, the facilitator has already processed the gathered information with representative employees, perhaps union representatives, to come to some conclusions about the goals of a training program. It is important that all stakeholders are in agreement on the goals of the diversity training program. Support of top management is particularly critical at this phase as it signals the importance of the project to the employees who will soon be students in the program.

\section{Step Five Is To Decide On A Training Format}

It is a well known fact that people learn in different ways, consequently it is recommended that the diversity training program use a variety of methods in order to effectively engage employees in the material. Some methods include web-based learning, videos, face-to-face presentations, role-play, small group discussions, and on-the-job examples. When considering group composition, it has been found that greater diversity among participants enhances the effectiveness of the training program by increasing the variety of viewpoints and decreasing the likelihood that some lone individual will be expected to speak on behalf of his or her diversity group. When considering program length, it is likely that diversity training programs should not be a single event. There is too much information to be assimilated for a half day or even full day program. It has been found that discussion groups and continuing training sessions help reinforce the information. (Ellis \& Sonnenfeld, 1994) Even better, organizations should incorporate diversity training into its other training programs as well to ensure diversity training will remain a long-term initiative. One-time diversity programs are often seen by employees as being of passing interest and not really important to the organization.

\section{Step Six Is To Train Managers First}

In all but the smallest organizations, employees must be divided into groups for training. The primary reason to train managers first is to get these people "on board" with the goals of diversity training and make sure that they are modeling the behavior that the organization wants to support. Managers can then demonstrate the benefits of the training to their own employees who will be trained subsequently.

\section{Step Seven Is To Train All Employees}

Diversity training is all about inclusion. There is no way to be effective at this training if only certain employees are singled out for the program. Training for all employees should be mandatory as this sends a very strong signal to employees that management is dedicated to the goals of the diversity training and that those goals are important for each and every employee.

\section{Finally, Step Eight Is To Build In Assessment And Feedback}

This final step is a pitfall for many training programs. Employees attend training and then it is over. No feedback, no assessment, little or no carry-over to the job. In order to ensure that an organization's diversity training program is accomplishing what it was intended to do, some method of assessments needs to be put into place before the training ever starts! Salomon \& Shork (2003) recommend taking surveys on a regular basis to ensure that the organization is on target with where they want to be in their implementation of diversity training. They also state that using diversity assessments in managers' performance evaluations are a means of providing feedback and ensuring effective implementation. Without means for evaluation, an organization cannot determine what is working well and where improvement needs to be made. Rynes \& Rosen (1995) also point out that absence of evaluation leads the employees to believe there is a lack of commitment on the part of management. Evaluation should be short-term as 
well as long-term and should be an ongoing process. Finally employees need to receive feedback regarding the meeting of diversity goals and how their own performance relates to those goals.

\section{CONCLUSION}

Diversity training programs will most likely continue in Corporate America as workplace diversity and globalization continue to increase. Organizations can choose to help their employees, managers and non-managers alike, "see past the spinach," by engaging well-qualified trainer/facilitators to design and implement diversity training programs that are tailor-made for the company and tied into organizational goals related to diversity. No single program will work for every organization. The diversity training program designed for a specific company must be visibly and enthusiastically supported by top management and all employees must be included. Continuous reinforcement by management will show employees that the organization is dedicated to providing, maintaining, and nurturing an inclusive workplace where each employee can realize his or her potential and goals.

\section{REFERENCES}

1. Anonymous (Sept. 2004). Apples and art helping diversity training. Training Journal 12.

2. Barbian, J. (February 2003). Moving toward diversity. Training. 40:2, 44+.

3. Bendick, M., Egan, M., and Lofhjelm, S. (2001). Workforce diversity training: From anti-discrimination compliance to organizational development. HR Human Resource Planning, 24:2, 10+.

4. Ellis, C. and Sonnenfeld, J. (1994). Diverse approaches to managing diversity. Human Resource Management 33:1, 79-109.

5. Fasig, L. (April 16, 2004). Diversity training leaves classroom for Web. Business Courier. 20:53, 3.

6. Hack, D. (July 11, 2004). NFL looking into use of diversity training/49ers' success provides model for treating issue. Houston Chronicle, 3.

7. Hemphill, H. and Haines, R. (1997). Discrimination, Harassment, and the Failure of Diversity Training: What to Do Now. Westport, CT: Quorum Books.

8. Karp, H. and Sammour, H. (2000). Workforce diversity: Choices in diversity training programs and dealing with resistance to diversity. College Student Journal, 34: 3, 451-458.

9. Katz, M. (Nov/Dec 2003). The current state of diversity training. Women in Business. 55:6, 26.

10. Kelly, D. (August 31, 2004). Need for diversity training is clear. Greensboro News Record, A6.

11. Management Training and Development (July 2001). Five hours of diversity training has a positive bottomline impact. Institute of Management and Administration, 1, 10-12, as cited in Nixon, J.; \& West, J. (Winter 2000). American addresses work force diversity. Business Forum, 25:1/2, 4+.

12. McLaughlin, J. and Clemons, L. (June 2004). Diversity training: The often-forgotten but necessary ingredient of any employment training program. PM. Public Management, 86:5, 32+.

13. Norheim, G. (August 27, 2004). In shadow of lawsuit, city promotes diversity training. Buffalo News, D3.

14. Overmyer Day, L. (1995). The pitfalls of diversity training. Training \& Development 49:12, 25-29.

15. Owens Corning Diversity Leadership Conference, retrieved December 18, 2004 from http://www.owenscorning.com/diversity2005/index.asp.

16. Roberson, L., Kulik, C., and Pepper, M. (December 2001). Designing effective diversity training: Influence of group composition and trainee experience. Journal of Organizational Behavior, 22:8, 871+.

17. Rynes, S. and Rosen, B. (1995). A field study of factors affecting the adoption and perceived success of diversity training. Personnel Psychology 48:2, 247-270.

18. Salomon, M. and Schork, J. (July/August, 2003). Turn diversity to your advantage. Research Technology Management 46:4, 37.

19. Swanson, D. (2002). Diversity programs: Attitude and realities in the contemporary corporate environment. Corporate Communications. 7:4, 257+.

20. The Mission of Southwest Airlines, retrieved December 8, 2004 online from http://www.southwest.com/ about_swa/mission.html.

21. Von Bergen, C. W., Soper, B., and Foster, T. (Summer 2002). Unintended negative effects of diversity management. Public Personnel Management, 31:2, 239+. 
22. Wentling, M. and Palma-Rivas, N. (1999). Components of effective diversity training programmes. International Journal of Training and Development 3:3, 215-226.

\section{NOTES}

